\title{
exo-Selective Catalysts for 1,3-Dipolar Nitrone Cycloaddition
}
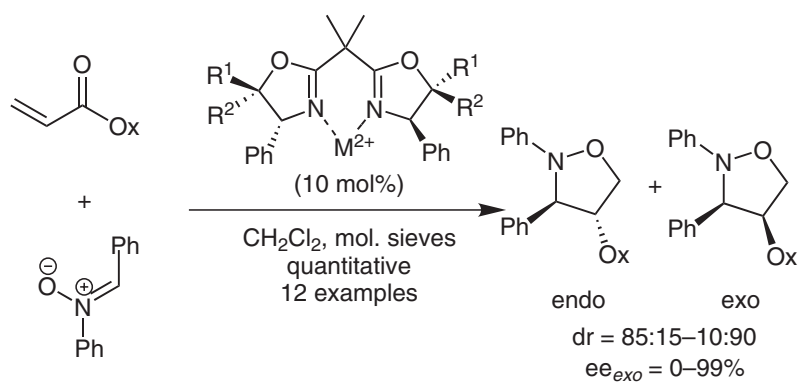

Significance: There are numerous methods for endo-selective cycloaddition reactions; however, few examples addressing exo-selectivity can be found. 1,3-Dipolar nitrone cycloadditions serve as templates for developing selective catalysts, as regio-, diastereo- and enantioselectivity must all be addressed. Using Ph-BOX ligands and Lewis acids such as $\mathrm{Mg}(\mathrm{II}), \mathrm{Co}(\mathrm{II}), \mathrm{Ni}(\mathrm{II})$ and $\mathrm{Zn}(\mathrm{II})$, selectivity can be tuned for the 1,3-dipolar cycloaddition between acryloyloxazolidinone and diphenyl nitrone. Under the optimal exo-selective conditions, >98:2 regioselectivity, 10:90 endo/exo selectivity and $99 \%$ ee $_{\text {exo }}$ was obtained with transdiphenyl-BOX ligand and $\mathrm{Ni}\left(\mathrm{ClO}_{4}\right)_{2}$ as Lewis acid.
Comment: All of the Lewis acid catalysts used produce quantitative conversion of the cycloaddition products. Addition of $4 \AA$ molecular sieves tends to favor formation of the exo-adduct, as well as the use of trans-disubstituted BOX ligands. One exception is the use of $\mathrm{Zn}(\mathrm{II})$, which showed reversed selectivity with the trans-ligands. In the absence of substituents on the 5-position of the BOX ligand, all cases show endo-selectivity. Overall, $\mathrm{Ni}(\mathrm{II})$ and $\mathrm{Mg}(\mathrm{II})$ performed the best, allowing access to the elusive exo-adduct. 